\title{
Psychological Conditions of Medical Personnel in Facing the Pandemic of Covid 19: Systematic Review
}

\author{
Anggia Riske Wijayanti*, Yosefina Dhale Pora, Ode Irman, Yosefina Nelista \\ and Yosephina Maria Hawa Keytimu \\ Lecturer of Faculty of Health Sciences of Nusa Nipa University, East Nusa Tenggara, Indonesia \\ *Corresponding author email: angga080308@gmail.com
}

\begin{abstract}
The Covid -19 outbreak brought global tensions because the transmission process was so fast that it caused health workers to experience psychological problems. Long-term psychological disorders lead to weakened social relationships, mental health problems, local and economic dynamics. Purpose Review of studies on the psychological stress of health workers caused by the COVID-19 pandemic. The method of searching for data using PubMed was carried out with the keywords COVID-19", "mental health", "stress", "health workers", "staff". Quantitative studies (including letters to editors) were published from January 2019 to March 2020. The quality of articles was analyzed by PRISMA and the Critical Ability Assessment Program (CASP). The results of 5 studies found that psychological disorders occurred in the covid ward, internal medicine, and other departmental wards such as symptoms of depression, anxiety, insomnia to fear. There are various questionnaires used. The sample size ranged between 80 and 2,299 participants. The severity of mental symptoms was influenced by age, working hours, occupation, and proximity to COVID-19 patients. Seeing the high frequency of psychological disorders that occur in health workers, it is necessary to provide psychological support and health education to facilitate coping for health workers.
\end{abstract}

Keywords: Psychological, medical personnel, pandemic covid-19

\section{INTRODUCTION}

Coronaviruses are a large family of viruses that cause illness ranging from mild to severe symptoms. The virus that causes COVID-19 is called Sars-CoV2. Common signs and symptoms of COVID-19 infection include acute respiratory symptoms such as fever, cough and shortness of breath are common signs and symptoms of ongoing COVID-19 infection, approximately 5-6 days with the longest incubation period of 14 days with the worst symptoms such as pneumonia, acute respiratory syndrome, kidney failure, and death. Severe cases of COVID-19 can cause pneumonia, acute respiratory syndrome, kidney failure and even death. Clinical signs and symptoms reported in the majority of cases were fever, with some cases having difficulty breathing, and X-rays showing a large pneumonia infiltrate in both lungs [1].

Since December 2019, an outbreak of 2019 coronavirus disease (COVID-19) in Wuhan, Hubei Province, China has raised worldwide concern as it spiraled into a pandemic [2]. On January 30, 2020, WHO has declared it a Public Health Emergency of International Concern. On March 2, 2020, Indonesia has reported 2 confirmed cases of COVID-19. On March 11, 2020, WHO has declared COVID-19 a pandemic. Where the number of confirmed cases and deaths increased dramatically. Thus COVID-19 presents a broad public health challenge, for the whole world.

Additional stressors during the covid-19 pandemic could be more severe with the Stigmatization of people who treat COVID-19 patients and their bodies, strict biosecurity measures (such as protective devices that restrict movement, physical isolation make it difficult to help people who are sick or stress, constant alertness and vigilance, Strict procedures prohibiting spontaneous and optional action), Higher job demands, including long working hours, an increase in the number of patients and changing best practices as information about COVID-19 develops, Increasingly difficult to get social support due to busy work schedules and community stigma against frontline officers, Lack of opportunities and manpower for basic care for themselves, Lack of information on long-term exposure to people infected with COVID-19, Fear of frontline officers will pass COVID-19 to family and friends because of field of work [3],[4].

The fear, worry and factors that cause pressure that continue to exist in the community during the COVID-19 pandemic can cause long-term consequences in the community and family which lead to weakening of social relations, local and economic dynamics, the emergence of stigma against surviving patients so that society rejects and Possible the emergence of anger and hostility towards government and frontline personnel, 
Possible doubts about information from the government and other authorities, Possible recurrence of mental health problems and drug abuse and other negative consequences because people avoid health facilities or cannot reach health workers for fear of contracting when treated [5].

Social stigma and social discrimination can be linked to COVID-19, for example against people who have been infected, their families and health workers and other frontline workers who have treated them. Steps must be taken to face stigma and discrimination in every phase of the COVID-19 emergency response. Reasonable attention must be paid to to help with the integration of those affected [4].

\section{METHODS}

The method used in this paper is systematic review. Systematic review is a systematic and critical way of thinking in examining various research articles using analysis, logic, argument, evaluation and information methods so as to produce good literature studies and evidence-based practice [6]. Reviews in this review literature use the PRISMA guidelines [7] .The goal is to assist the author in selecting the literature obtained. The purpose of this paper is to see the psychological condition of medical personnel in the face of the Covid 19 pandemic. Search data from this writing using the PubMed database. The key words used are "Covid 19" AND "mental health" AND "stress" AND "medical perconel" AND "staff". The words can change from one another, or can form a certain combination so that you can find a more specific search. Inclusion criteria: (1) articles published from January 2019-2020 with articles in English and Chinese, (2) full text, (3) types of quantitative article designs including "letters to editors", (4) search studies addressing psychological conditions medical personnel in the covid pandemic 19. Exclusion criteria such as (1) Qualitative, reviews, only abstracts (2) articles published before January 2019. The next step is to analyze the quality of the research articles selected by applying the Critical Ability Assessment Program (CASP) and Quality Assessment as instruments to assess the risk of bias of the selected study [6]. Based on the CASP results, 5 articles were recorded by the authors.

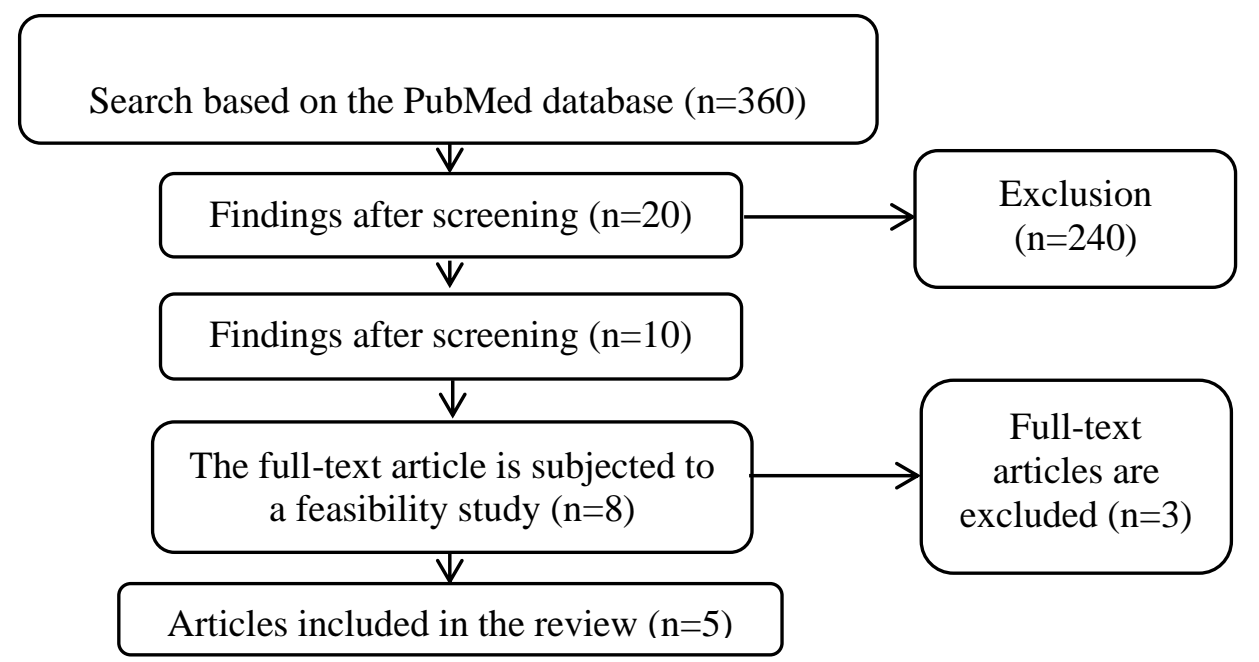

FIGURE 1. Literature search flowcharts

\section{RESULTS}

360 articles were obtained based on the Pubmed data base, 20 articles according to the inclusion criteria then another screening was carried out regarding the relevance of the articles for this systematic review and excluded 343 articles, 5 articles were selected that met the requirements whose quality was evaluated by the Critical Assessment Skills Program (CASP). Of the five articles, the research was conducted in China, which is the first carrier of the Covid 19 pandemic (Table 1). 
TABLE 1. Synthesis Grid

\begin{tabular}{|c|c|c|c|c|c|}
\hline No & Author and year & Research Area / Date & Sample size & Result & Comments \\
\hline 1 & $\begin{array}{l}\text { Liang, Chen, } \\
\text { Zheng, \& Liu, } \\
\text { (2020) }\end{array}$ & $\begin{array}{c}\text { Guangdong Province, } \\
\text { China } \\
3 \text { to } 21 \text { February } \\
2020\end{array}$ & $\begin{array}{l}\mathrm{N}=80 \text { clinic } \\
\text { staff: } \\
\text { Doctor }: 23 \\
\text { Covid nurse } \\
19: 36 \\
\text { the other }: 21\end{array}$ & $\begin{array}{l}\text { - There is no } \\
\text { difference in } \\
\text { depression and fear } \\
\text { symptoms between } \\
\text { staff in the Covid } 19 \\
\text { department and other } \\
\text { departments } \\
\text { - Advice and advice } \\
\text { to avoid mental stress }\end{array}$ & $\begin{array}{l}\text { - Nursing staff } \\
\text { from other } \\
\text { departments } \\
\text { who do not care } \\
\text { for Covid } 19 \\
\text { patients also feel } \\
\text { stress and } \\
\text { depression } \\
\text { - Support } \\
\text { measures are } \\
\text { very necessary }\end{array}$ \\
\hline 2 & $\begin{array}{l}\text { Mo et al., } \\
(2020)\end{array}$ & $\begin{array}{c}\text { Wuhan, China } \\
21 \text { Februari } 2020\end{array}$ & $\begin{array}{l}\mathrm{N}=180 \text { covid } \\
\text { nurses } 19\end{array}$ & $\begin{array}{l}\text { - The main factors } \\
\text { influencing nurses' } \\
\text { stress were: about } \\
\text { children, working } \\
\text { hours per week and } \\
\text { anxiety ( } \mathrm{p}=0.000 \text {, } \\
0.048,0.000, \\
\text { respectively). }\end{array}$ & $\begin{array}{c}\text { - Required social } \\
\text { support } \\
\text { - Time } \\
\text { management }\end{array}$ \\
\hline 3 & $\begin{array}{c}\text { Kang et al., } \\
(2020)\end{array}$ & $\begin{array}{c}\text { Wuhan, China } \\
\text { 29 Januari - } 4 \text { Feb } \\
2020\end{array}$ & $\begin{array}{c}\mathrm{N}=994 \\
\text { Doctor } 183 \\
\text { Nurse } 811\end{array}$ & $\begin{array}{l}\text { Mental disorders } \\
\text { were found in } 4 \\
\text { groups: subliminal } \\
36 \% \text {, slight } 34.4 \% \text {, } \\
\text { moderate } 22.4 \%, \\
\text { severe } 6.2 \% \text { and } \\
\text { young women very } \\
\text { quickly affected }\end{array}$ & $\begin{array}{l}\text { We need a } \\
\text { better crisis } \\
\text { preparation }\end{array}$ \\
\hline 4 & $\begin{array}{l}\text { Lu, Wang, Lin, } \\
\text { \& Li, (2020) }\end{array}$ & $\begin{array}{c}\text { Fujian, China } \\
25-26 \text { Feb } 2020\end{array}$ & $\begin{array}{c}\mathrm{N}=2,299 \\
\text { Medical staff } \\
2,042 \\
\text { Administrative } \\
\text { staff } 257\end{array}$ & $\begin{array}{l}\text { It was found that the } \\
\text { value of fear, anxiety } \\
\text { and depression from } \\
\text { medical staff was } \\
\text { higher than that of } \\
\text { administrative staff, } \\
\text { namely fear } \\
\text { (moderate and } \\
\text { severe) } 70.6 \% \text {, } \\
\text { anxiety (mild and } \\
\text { moderate) } 22.6 \% \text {, } \\
\text { difficulty } 2.9 \% \text { and } \\
\text { depression (mild and } \\
\text { moderate ) } 11.8 \% \\
\text { difficult } 0.3 \%\end{array}$ & $\begin{array}{l}\text { An effective } \\
\text { assistance } \\
\text { strategy is } \\
\text { needed }\end{array}$ \\
\hline 5 & Wu et al (2020) & $\begin{array}{c}\text { Wuhan, China } \\
\text { 13-17 Maret } 2020\end{array}$ & $\mathrm{~N}=190$ staf & $\begin{array}{l}\text { The front-line group } \\
\text { had a lower burnout } \\
\text { frequency }(13 \% \\
\text { versus } 39 \%, \mathrm{P}< \\
.0001) \text {, and were less } \\
\text { worried about being } \\
\text { infected than the } \\
\text { typical environmental } \\
\text { group. }\end{array}$ & $\begin{array}{l}\text { Staff with even } \\
\text { no exposure to } \\
\text { COVID-19 still } \\
\text { need help }\end{array}$ \\
\hline
\end{tabular}


Research conducted by Liang, Chen, Zheng, \& Liu, (2020) is the result of research submitted directly in the form of a letter to the editor [8]. In this study, researchers wanted to assess how the mental health of medical staff who faced the COVID-19 pandemic and other departments in one of the largest hospitals in Guangdong Province, China. Mental health assessed in research Y. Liang et al is a scale of depression and anxiety levels from doctors, nurses in the Covid 19 isolation room and other staff in other departments such as in the department of medicine and critical care, the department of cardiology and the ICU which lasted from 3 to 21 February 2020. The questionnaire used to rate the depression scale is the Self Rating Depression Scale (SDS) while Self Rating Anxiety Scale (SAS) to assess anxiety. Liang, Chen, Zheng, \& Liu, (2020) In his research, it was found that some staff experienced depressive symptoms that exceeded the normal threshold value and there was no significant difference in depression and anxiety scores among COVID 19 staff and other departments [8].

Further research conducted by Mo et al., (2020) have one variable in common with previous research conducted by Liang et al (2020). In this research Mo et al, wanted to see the level of stress and anxiety among Chinese nurses in Wuhan [9]. With a cross sectional method, researchers used a questionnaire (SOS) to assess the stress scale and Self Rating Anxiety Scale (SAS) for anxiety with 180 samples. In China the results of the stress scale assessment questionnaire have a Cronbach alpha value and good validity $(0.936 \& 0.860)$ with a score in the range 22 110 where the higher the score, the greater the pressure. Whereas SAS has 20 question items with a four-point scale, which evaluates the frequency of symptoms. The value "1" indicates no or limited time, "4" indicates most or all of the time. The higher the score, the worse the anxiety. Online survey (via website platform) sent to the head of the room which will then be passed on to the nurses. Participants can fill out a questionnaire via a computer or smartphone which includes a letter of consent, research objectives, anonymity and confidentiality. Subsequent research showed a positive correlation between stress and anxiety scores in the nurse group $(\mathrm{r}=0,676, \mathrm{p}<0.05)$. Anxiety that causes stress leads to more answers to the item that there is a nurse who is the only child in the family and the amount of work per week is long enough to make those who work think about the condition of their family [9]

The same cross sectional study was also conducted by Kang et al (2020) in Wuhan, China which lasted 7 days of research. Highlight the mental health problems of medics, namely doctors and nurses who distribute questionnaires online. The questionnaire given consisted of 4 types to measure mental health problems among the medics The patient health questionnaire (PHQ-9) to assess depression, Generalized Anxiety Disorder (GAD-7) for anxiety, Insomnia Severity Index (ISI) for insomnia disorders and Impact of Event Scale Revised (IESR) to assess responses to stressful life events. A sample of 994 was able to complete the questionnaire well online. Research conducted in Wuhan subsequently obtained data that most mental health was on the threshold (average PHQ-9 : 2,4) which is equal to $34,4 \%$ although there are also serious mental health problems (mean PHQ-9 : 15,1) amounting to $6,2 \%$, and the rest are in mild mental health $(34,4 \&)$ and moderate $(22,4 \%)$. The heaviest burden recorded was dominated by women [10]

Lu, Wang, Lin, \& Li, (2020) in his research conducted at the Fujian provincial hospital emphasized the same problem as the previous research, namely fear, anxiety and depression [11]. The questionnaire was distributed in just 2 days and was immediately filled in completely. Fear was measured using a questionnaire The Numeric Rating Scale (NRS), with the level of fear using 0-10 points with a higher score indicates a greater fear. Anxiety is assessed by Hamilton Anxiety Scale (HAMA) starting with no anxiety to severe anxiety. While depression uses a questionnaire Hamilton Depression Scale (HAMD) with levels of depression ranging from normal to major depression. In this study, which was conducted at the Fujian Hospital, it was found that the level of fear, anxiety and depression was significantly different among medical staff and administrative staff. The fear scale score increased in medical staff compared to administrative staff by $(\mathrm{p}<0,001)$. Scores also improved for the level of crisis and depression which was higher for medical staff than for administrative staff ( $p 0,015$ and p 0,029). This makes medical staff more susceptible to psychological disorders [11].

Subsequent research was conducted by Wu et al (2020) Where in the research that was conducted for 4 days, this was a different study from previous studies, namely wanting to see a comparison [12]. Researchers wanted to assess the comparison of the frequency of fatigue between doctors and nurses in the oncology ward with other staff who worked in a normal ward at one hospital during the Covid 19 pandemic. A survey with 49 questions was given by members of the medical staff on the frontline of Covid 19 and ordinary wards. Questionnaire Maslach Burnout Inventory (MBI) is a questionnaire 
used to assess the frequency of fatigue, which was completely filled out by medical staff for 5 days as many as 190 out of 220 invited participants who were able to complete the survey.Subsequent research conducted investigated the scale of fatigue between medical staff in the oncology ward and staff groups in ordinary wards. The result is that the fatigue scale of the oncology ward medical staff has a lower score than the staff in the normal ward $(13 \%$ proportional 39\%, $\mathrm{p}<.0001)$ [12].

\section{DISCUSSION}

At this writing, various studies were obtained that examined the psychological status of hospital workers. It was found that various kinds of psychological disorders that arise with high and low score scores, the sample ranges from 80-2299 respondents by distributing questionnaires either filling in directly or online. There are various questionnaires used to measure psychological status. Based on the 5 studies reviewed by the authors, most of the results showed that medical staff experienced psychological disorders. Psychological disorders such as depression, stress, anxiety, and fear [8], [9], [10], [11], [12].

The causes include the increase in case reports every day, the number of long working hours and thinking about the condition of the family at home, including about their parents at home. There has been an increase in reported number of cases due to the corona virus disease outbreak in Wuhan, Hubel China since December 2019 has increased [13]. The number of patients who reached more than 75,000 confirmed cases as of February 29 in China [2]. It is also in line with other studies which say that negative pressure can cause disease consequences, where the sympathetic adrenal medulla system and the hypothalamus pituitary adrenal can be active when someone experiences acute psychological stress[14]. For decades, for example viral hepatitis and HIV can cause infectious death, but health professionals (radiologists, pathologists and nurses) understand that as long as they are careful in contact with their patients' fluids they can still work even more hours [15].

Long working hours certainly make the risk of exposure greater because of the difference from the COVID 19 disease itself, where many individuals are infected with minimal or no symptoms of illness during infection at the beginning of infection who are not aware of the patient. indiscriminately thereby stressing the workers [16]. Long working hours will certainly have an impact on the family at home, the differences in the characteristics of the COVID 19 disease also make them have to be separated from their family for a long time. According to Su Qian, (2015) in order to reduce mental stress and lift psychological barriers, social support is an important factor so that psychological resilience can be built. Nurses who are only the only child in the family are concerned about the health of family members and fear that if they die from COVID 19, their parents will lose their only child. thus the need to activate social support among nurses [17].

The mental health of the medical personnel should not be ignored, there are several therapies that can be carried out during a pandemic by staff of all ages such as fulfilling daily living necessities, preemployment training, recreational activities and psychological counseling [18]. Access psychological material (such as books on mental health) and access psychological resources available through the media independently [10]. Opened consulting services in hospitals on mental health management for medical staff [19]. According to Wong (2007) in an emergency the nurse's attitude is to mobilize enthusiasm and thoroughness by strengthening the training and preparation of specialists to relieve the psychological stress of medical staff. Other than that, According to Y. Mo et al (2010) the nurse must keep in touch with family and friends. families can be facilitated with the help of digital telecommunications as well as the presence of community staff who visit the nurse's family directly to provide assistance to families in need so that the nurse can concentrate on working [9].

\section{CONCLUSION}

Symptoms of psychological disorders were found on the covid ward, internal medicine, and other departmental wards such as depression, anxiety, insomnia to fear which is influenced by age, working hours, work and closeness to COVID-19 patients. Seeing the high frequency of mental symptoms that occur in health workers, it is necessary to provide psychological support and health education to facilitate coping for health workers.

\section{ACKNOWLEDGMENTS}

This article is presented in the University of Muhammadiyah Gresik Conference: Health, Social Science and Humanities (HSSH), Enhancing Human Resources Productivity through Engineering, Social Science, and Health during Covid-19 Pandemic. 


\section{REFERENCES}

[1] Kementerian Kesehatan Republik Indonesia., "Pedoman Pencegahan Dan Pengendalian Coronavirus Disease (Covid19) Revisi Ke-4," 2020.

[2] National Health Commission of the People"s Republic of China, "National Health Commission of the People"s Republic of China," The Latest Situation of New Coronavirus Pneumonia, 2020.

[3] L. L. Bao Y, Sun Y, Meng S, Shi J, “2019nCoV epidemic: address mental health care to empower society.," vol. Lancet . F, 2020.

[4] National Bureau of Health and Disease Control and Prevention, "Response to new coronavirus pneumonia: Psychological adjustment guide," 2020 .

[5] IFRC, "Personal communication," Hong Kong, 2020.

[6] C. T. Polit, D. F., \& Beck, Essentials of Nursing Research, Appraising Evidence for Nursing Practice. Wolters Kluwer Health., 2010.

[7] H. Kamioka, "Preferred reporting items for systematic review and meta-analysis protocols (prisma-p) 2015 statement," Japanese Pharmacol. Ther., vol. 47, no. 8, pp. 1177-1185, 2019.

[8] Y. Liang, M. Chen, X. Zheng, and J. Liu, "Screening for Chinese medical staff mental health by SDS and SAS during the outbreak of COVID-19," J. Psychosom. Res., vol. 133, no. March, pp. 16-18, 2020.

[9] Y. Mo et al., "Work stress among Chinese nurses to support Wuhan for fighting against the COVID-19 epidemic," J. Nurs. Manag., 2020.

[10] L. Kang et al., "Impact on mental health and perceptions of psychological care among medical and nursing staff in Wuhan during the 2019 novel coronavirus disease outbreak: A cross-sectional study," Brain. Behav. Immun., no. March, pp. 1-7, 2020.

[11] W. Lu, H. Wang, Y. Lin, and L. Li, "Psychological status of medical workforce during the COVID-19 pandemic: A crosssectional study," Psychiatry Res., vol. 288, no. April, pp. 1-5, 2020.

[12] Y. Wu et al., "A comparison of burnout frequency among oncology physicians and nurses working on the front lines and usual wards during the COVID-19 epidemic in Wuhan, China," J. Pain Symptom Manage., 2020.
[13] C. Wang, P. W. Horby, F. G. Hayden, and G. F. Gao, "A novel coronavirus outbreak of global health concern," Lancet, vol. 395, no. 10223, pp. 470-473, 2020.

[14] A. I. Turner, "Psychological stress reactivity and future health and disease outcomes: a systematic review of prospective evidence.," Psychoneuroendocrinology, vol. 114, 10459, 2020.

[15] Chowell, G., et al., "Transmission characteristics of MERS and SARS in the healthcare setting: a comparative study," BMC Med. Ethics, vol. 13, 210, 2015.

[16] Y. Bai, "Presumed asymptomatic carrier transmission of COVID-19.," JAMA Surg., 2020.

[17] G. L. Su Qian, "Relationship between psychological elasticity, workstress a nd social support of clinical female nurses," Chinese Occup. Med., pp. 42 (1):55-58., 2015.

[18] Y. L. Qiongni Chen, Mining Liang, "Mental health care for medical staff in China during the COVID-19 outbreak," Lancet Psychiatry, 2020.

[19] W. Jiang, X., Deng, L., Zhu, Y., Ji, H., Tao, L., Liu, L., Yang, D., Ji, "Psychological crisis intervention during the outbreak period of new coronavirus pneumonia from experience in Shanghai," Psychiatry Res., vol. 286, 11290, 2020. 